\title{
Effects of Different Wire Drawing Routes on Grain Boundary Character Distribution, Microtexture, $\delta$-Phase Precipitation, Grain Size and Room Temperature Mechanical Behavior of Alloy 718
}

\author{
Luiz Maurício Barreto de Azevedo ${ }^{a^{*}}$ (D), Arthur Ribeiro Figueiredo ${ }^{a}$ (), Flavia da Cruz Gallo ${ }^{a}$ (D),

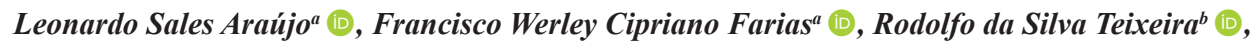 \\ Thiago Marques Ivaniskic ${ }^{(1)}$, Luiz Henrique de Almeida ${ }^{a}\left(\mathbb{D}\right.$, Matheus Campolina Mendes ${ }^{d}(\mathbb{C})$ \\ ${ }^{a}$ Universidade Federal do Rio de Janeiro, Instituto Alberto Luiz Coimbra de Pós-Graduação e Pesquisa \\ de Engenharia, Programa de Engenharia Metalúrgica e de Materiais, Av. Horácio Macedo, 2030, \\ Cidade Universitária, 21941-972, Rio de Janeiro, RJ, Brasil \\ ${ }^{b}$ Instituto Militar de Engenharia-IME, Departamento de Ciências dos Materiais, Praça General \\ Tibúrcio, Urca, 22290-270, Rio de Janeiro, RJ, Brasil \\ cPrograma de Pós-Graduação em Engenharia de Minas, Metalúrgica e Materiais, Universidade \\ Federal do Rio Grande do Sul, Av. Paulo Gama, 110, Farroupilha, 90040-060, Porto Alegre, RS, Brasil. \\ ${ }^{d}$ Centro Federal de Educação Tecnológica Celso Suckow da Fonseca, Departamento de Engenharia \\ Mecânica, Avenida Maracanã, 298/299, Maracanã, 20271-110, Rio de Janeiro, RJ, Brasil
}

Received: March 29, 2020; Revised: May 16, 2020; Accepted: May 27, 2020

\begin{abstract}
Over the last decades, alloy 718 usage has expanded and requirements imposed by its industrial applications became more critical. The knowledge about grain boundary character distribution (GBCD) in alloy 718 and its effect on properties improvement is mostly built based on iterative processing through cold rolling steps interspersed with solution annealing. Alloy 718 is found in the industry in many different forms and geometries, and fabricated by multiple thermomechanical processes such as wire drawing, rolling, forging or extrusion. The present study focused on understanding how wires respond to deformation mode related to drawing in regard to GBCD evolution, crystallographic orientation, precipitation of $\delta$-phase and grain size. Lastly, assessing the resulting mechanical properties. The findings show that microstructural evolution is a consequence of competing mechanisms such as strain induced boundary migration, recrystallization, grain growth and phase precipitation. The deformation gradient along wire cross section plays an important role in affecting microstructural features, such as $\delta$ precipitation, GBCD and microtexture.
\end{abstract}

Keywords: Alloy 718, Grain boundary character distribution, Microtexture, Wire drawing, $\delta$-phase.

\section{Introduction}

The nickel-based superalloy 718 is commonly used in the oil and gas, nuclear and aerospace industries in structural applications that combine a wide range of temperatures with mechanical solicitations (high yield strength, toughness and creep resistances), as well as corrosive environments ${ }^{1-4}$. This alloy has a face centered cubic (FCC) matrix $(\gamma)$ with medium to low stacking fault energy (SFE) ${ }^{5}$. The relatively high strength of this material is owed to the precipitation of the metastable coherent phase $\gamma$ " $\left(\mathrm{BCT}-\mathrm{Ni}_{3} \mathrm{Nb}-\mathrm{DO}_{22}\right)$ and the stable coherent $\gamma^{\prime}\left(\mathrm{FCC}-\mathrm{Ni}_{3}(\mathrm{Al}, \mathrm{Ti})-\mathrm{L}_{2}\right)$ in the $\gamma$ matrix $^{6}$. Besides these phases, the precipitation of the stable $\delta$-phase (Orthorhombic $-\mathrm{Ni}_{3} \mathrm{Nb}-\mathrm{DO}_{\mathrm{a}}$ ) may occur ${ }^{7}$, which can precipitate following the dissolution of the metastable $\gamma$ " phase or directly from the $\gamma$ matrix $^{7-9}$. The influence of the $\delta$-phase on the mechanical properties of the nickel-based superalloy 718 is ambiguous. According

*e-mail: luizmauricio@metalmat.ufrj.br to Singh et al..$^{10}$, the $\delta$-phase precipitates at grain boundaries during the recrystallization process, which limits the grain boundaries mobility and controls alloy's grain size. In contrast, Medeiros et al. ${ }^{11}$ related the loss in ductility due to the presence of the $\delta$-phase since these particles work as preferential sites for voids and cracks during mechanical solicitations.

Alloy 718 is often susceptible to intergranular failures of different nature, such as oxygen assisted intergranular cracking (OAIC) and hydrogen embrittlement ${ }^{12,13}$. Hence, some authors propose the deliberated manipulation of grain boundary character distribution (GBCD) in order to mitigate those phenomena by breaking the connectivity of random high angle boundaries, more prone to crack propagation ${ }^{14,15}$. That manipulation is directly related to $\Sigma 3$ twin boundary mobility and interaction through a mechanism that is known as " $\Sigma 3$ regeneration model", where twins interact, generating new $\Sigma 9$ and $\Sigma 27$ boundaries segments ${ }^{16}$. Increase the length 
fraction of $\Sigma 3^{\mathrm{n}}$ boundaries $(\Sigma 3+\Sigma 9+\Sigma 27)$, in replacement of random $\mathrm{HAB}$, is achieved by subjecting low stacking fault energy (SFE) materials to iterative thermomechanical processing (TMP), alternating successive cycles of deformation followed by solution annealing ${ }^{8,15}$. So far, there is still some uncertainty in the literature regarding the mechanism accountable to multiple twinning: recrystallization, grain growth or grain boundary migration induced by deformation ${ }^{17,18}$.

After a literature review, it was evidenced that most knowledge about GBCD in alloy 718 is built based on multiple cycles of cold rolling followed by solution annealing ${ }^{8,11,19,20}$. However, alloy 718 can be fabricated as different geometries and by different thermomechanical process as wire drawing or extrusion. Wires of alloy 718 can be used, for instance, to fabricate high temperature coil springs. Therefore, assessing alloy's response to different formation mechanisms in regard to GBCD evolution is needed.

Other materials, such as high purity $\mathrm{Cu}$, have already had their GBCD evolution studied after being subjected to different deformation modes like wire drawing. For example, Baudin et $a l .{ }^{21}$ observed the higher in length fraction of $\Sigma 3^{\mathrm{n}}$ for a low cross-sectional area reduction. Opposingly, Matsushita et al. ${ }^{22}$ have observed the most relevant increase in $\Sigma 3^{\mathrm{n}}$ for a greater area reduction. Yet, those controversies evidence how little understanding is available regarding the influence of wire drawing iterative thermomechanical processing on material's GBCD.

Thus, the goal of the present study is to investigate the applicability of GBCD manipulation via wire drawing, subjecting alloy 718 to iterative processing routes analogous to the ones already established in the literature, by means of cold rolling. The deformation mode related to drawing and its effect on GBCD as well as on crystallographic orientation were studied together with the influence of $\delta$-phase on grain size and consequently

Table 1. Chemical composition of alloy 718 rolled wire as-received.

\begin{tabular}{cccccccc}
\hline $\boldsymbol{N i}$ & $\boldsymbol{C r}$ & $\boldsymbol{N b}$ & $\boldsymbol{M o}$ & $\boldsymbol{T i}$ & $\boldsymbol{A l}$ & $\boldsymbol{C o}$ & $\boldsymbol{C}$ \\
\hline 52.86 & 18.44 & 5.16 & 3.02 & 0.94 & 0.54 & 0.19 & 0.03 \\
\hline $\boldsymbol{M n}$ & $\boldsymbol{S i}$ & $\boldsymbol{P}$ & $\boldsymbol{S}$ & $\boldsymbol{B}$ & $\boldsymbol{C u}$ & $\boldsymbol{F e}$ & - \\
\hline 0.06 & 0.06 & 0.007 & $<0.0005$ & 0.004 & 0.006 & 18.36 & - \\
\hline
\end{tabular}

Table 2. Commercial drawing dies geometries.

\begin{tabular}{cccc}
\hline $\begin{array}{c}\text { Approuch } \\
\text { angle }(2 \beta)\end{array}$ & $\begin{array}{c}\text { Reduction } \\
\text { angle }(2 \alpha)\end{array}$ & $\begin{array}{c}\text { Exit angle } \\
(2 \gamma)\end{array}$ & $\begin{array}{c}\text { Bearing } \\
\text { length }(\boldsymbol{H c})\end{array}$ \\
\hline $75^{\circ}$ & $9^{\circ}$ & $75^{\circ}$ & $3 \mathrm{~mm}$ \\
\hline
\end{tabular}

on resulting mechanical properties. Alloy 718 wires were subjected to two different iterative thermomechanical processing, alternating cycles of drawing followed by solution annealing both at sub and super $\delta$-solvus temperatures.

\section{Materials and Methods}

\subsection{Material and processing}

The as-received material was supplied as a wire rod of alloy 718 produced by hot rolling with $6.7 \mathrm{~mm}$ diameter, with chemical composition as presented in Table 1.

Two distinct thermomechanical routes were applied encompassing three steps of wire drawing with area reductions of $24.4 \%, 17.7 \%$ and $15.4 \%$, respectively, followed by solution annealing after each cycle at two different temperatures, by that designated as routes A and B. The commercial drawing dies diameters and geometries are listed in Table 2, according to manufacturer specifications.

The $\delta$-phase solvus temperature was determined through thermodynamic calculation, using the Thermo-calc ${ }^{\circledR}$ $2017 \mathrm{~b}$ software and the TCNI8 database ${ }^{23}$ and established as $1030^{\circ} \mathrm{C}$. Therefore, the solution annealing temperatures were defined based on the calculated $\delta$-phase solvus temperature data. The as-received material was initially solution heat treated above $\delta$-solvus temperature, at $1050^{\circ} \mathrm{C}$. Route $\mathrm{A}$ consisted of solution annealing at sub $\delta$-solvus temperature of $975^{\circ} \mathrm{C}$, for 15 minutes, after each step of wire drawing. Route B consisted of a step of solution annealing at super $\delta$-solvus temperature of $1050^{\circ} \mathrm{C}$, for 30 minutes, after the two first steps of wire drawing. The final step of wire drawing was followed by solution annealing at $975^{\circ} \mathrm{C}$ for 75 minutes. This final step under $\delta$-phase solvus temperature was made in order to inhibit grain growth and, consequently, maintain a fine grain size distribution. Ultimately, samples from both routes were subjected to aging heat treatments in order to promote the precipitation of the hardening precipitates $\gamma^{\prime}$ and $\gamma$ ', comprising 285 minutes at $760^{\circ} \mathrm{C}$, followed by controlled cooling at rate $0.67^{\circ} \mathrm{C} / \mathrm{min}$ up to $650^{\circ} \mathrm{C}$, being held for 75 minutes before air cooling. The thermomechanical processing routes A and B are depicted in Figure 1.

\subsection{Numerical simulation}

Numerical simulation sought to compute the resulting effective strain distribution along wire longitudinal and transversal directions, during each wire drawing

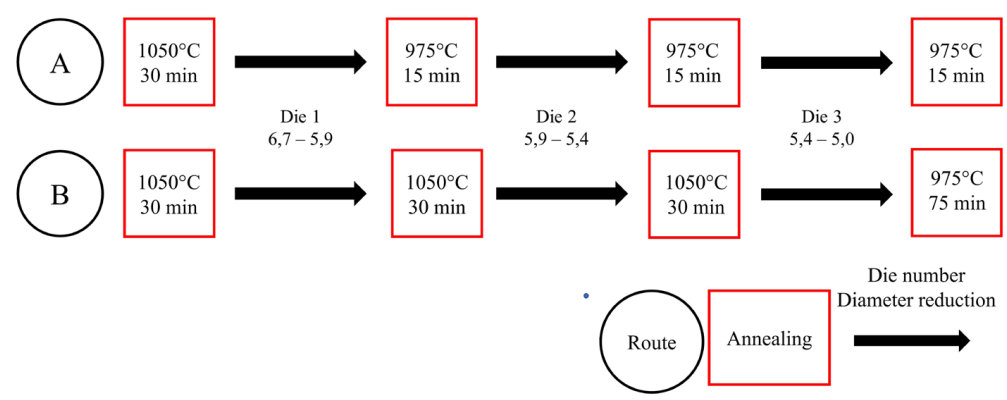

Figure 1. Scheme showing the thermomechanical processing routes applied to the alloy 718 wires. Black circles indicate the route identification, red rectangles indicate the annealing temperature and time, and black arrows indicate die number and wire diameter reduction in millimeters for each step. 
step. Finite Element Method (FEM) were performed by DEFORM $^{\circledR}$ commercial software package. The asymmetric model is shown in Figure 2, which was created from three-dimensional numerical simulation. Three reductions steps were measured, as described previously in Figure 1. The first and the second were $3 \mathrm{~mm}$ long, configuring a longer length in the die's calibration zone. The last reduction was $2.5 \mathrm{~mm}$ long. The considered speed of each drawing pass was $100 \mathrm{~mm} / \mathrm{s}$.

For these analyzes, the same mechanical properties were assumed for the material between drawing passes. It implies that the deformation hardening effect was not taken into consideration from one pass to next, which is adequate since annealing heat treatment was performed between each deformation pass. This work is based on a model that assumes that the wire is a deformable element, therefore it was considered as a tetrahedral volumetric mesh. While the wire drawing die surface was considered as a rigid element, therefore, a triangular mesh was used. FEM was based on materials and processing parameters, which are listed in Table 3 . The as-received material was subjected to uniaxial tensile testing, with strain rate of $7.06 * 10^{-4} \mathrm{~s}^{-1}$, and the stress versus strain dataset was uploaded in the software database in order to validate the power law. The isotropic hardening rule and the yield function type Von Mises were considered during deformation in this work.

\subsection{Microstructural characterization}

\subsubsection{Scanning electron microscopy}

Quantification of $\delta$-phase was based on five different fields of image, randomly distributed on sample surface from the center to half the wire radius $(1 / 2 \mathrm{R})$. Vega $3 \mathrm{LMU}$ Tescan scanning electron microscope (SEM) was used in the backscattered electron (BSE) mode for atomic contrast, with $20 \mathrm{KV}$ high voltage and 2000x nominal magnification. The solution treated sample was analyzed for $\delta$-phase quantification, after grinding up to 1200 mesh, polishing with diamond paste up to $1 \mu \mathrm{m}$ and no etching. SEM/BSE images were processed for $\delta$ particles area measurements in Image $\mathrm{J}$, an open source software, through binarization of the original images.

\subsubsection{Electron backscattered diffraction}

The aged samples were prepared for electron backscattered diffraction (EBSD) imaging through grinding with 1200 mesh sandpaper and chemical electropolishing using double jet technique in a Struers Tenupol 5 polishing apparatus with a solution of $9 \%$ perchloric acid $\left(\mathrm{HClO}_{4}\right)$ and $91 \%$ ethanol, at $-20^{\circ} \mathrm{C}$ temperature, $20.5 \mathrm{kV}$ and 45 seconds of exposure time. Electropolishing resulted in a restricted $2 \mathrm{~mm}$ diameter polished area in each sample, where two distinct fields were

Table 3. List of Process Parameters pre-defined for numerical simulation.

\begin{tabular}{cc}
\hline Imput Parameter & Value \\
\hline Initial Diameter $/$ Step $\left(\mathrm{D}_{\mathrm{o}}\right)$ & $6.7 / 5.9 / 5.4 \mathrm{~mm}$ \\
\hline Final Diamenter $/$ Step $\left(\mathrm{D}_{\mathrm{f}}\right)$ & $5.9 / 5.4 / 5.0 \mathrm{~mm}$ \\
\hline Reduction $/$ Step & $11.9 / 8.4 / 7.4 \%$ \\
\hline Room temperature $\left({ }^{\circ} \mathrm{C}\right)$ & 20 \\
\hline Die temperature $\left({ }^{\circ} \mathrm{C}\right)$ & 20 \\
\hline Heat transfer coefficient $\left(\mathrm{W} / \mathrm{m}^{2} . \mathrm{K}\right)$ & 1000 \\
\hline Coulomb coefficient & 0.1 \\
\hline Tool speed $(\mathrm{mm} / \mathrm{s})$ & $100 / 50$ \\
\hline Hardening rule & Isotropic \\
\hline Yield Function Type & Von Mises \\
\hline Flow Curve Equation & $\sigma_{w h}=1955.015 e^{-0.0009} \varepsilon^{0.2514} e^{\frac{-0.0001}{\varepsilon} \dot{\varepsilon}^{0.00001}}$ \\
\hline Model & Langragian \\
\hline
\end{tabular}

(a)

1 - Bearing surface 2 - Approach angle

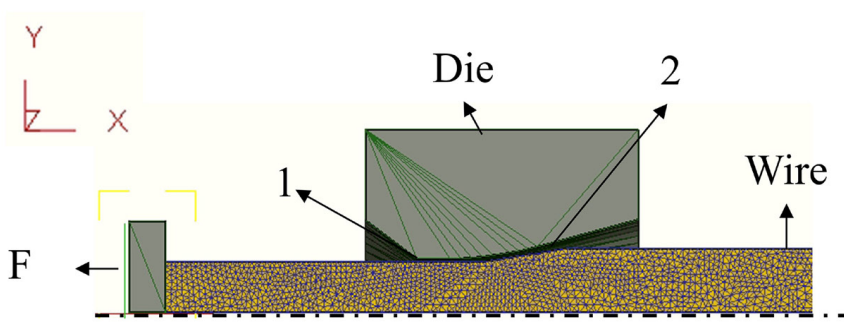

Figure 2. Standard simulation model $(\mathrm{F}=$ Drawing Force $)$. (b)

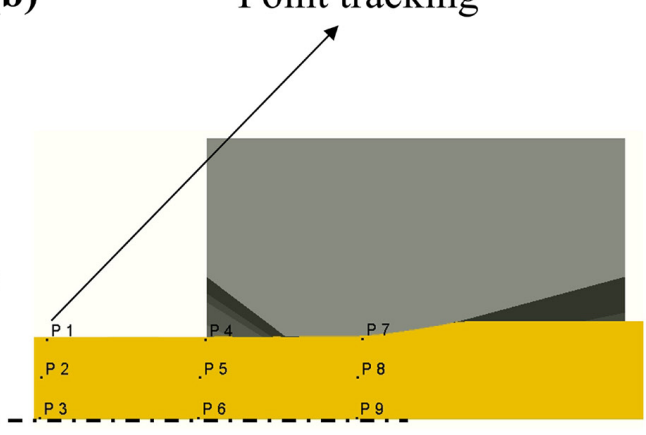


EBSD scanned for each TMP route: in the center and in half of the wire radius $(1 / 2 \mathrm{R})$.

EBSD scanning was performed in two different instruments: route A samples were scanned in a CAMSCAN $3200 \mathrm{LV}$ SEM, with EBSD Oxford camera and HKL system; route B samples were scanned in a QUANTA 250 SEM equipped with field emission gun (FEG) and Bruker detectors controlled by CrystAlign software. Both routes were investigated with a step size of $1 \mu \mathrm{m}$.

Scans datasets were processed using MTEX 5.1.1, that encompasses quantitative texture analysis ${ }^{24}$. From the EBSD data it was possible to analyze the grain size through the linear intercept method ${ }^{25}$, the identification and classification of CSL boundaries, which was based on Brandon's criteria to define limits to coincidence lattice sites ${ }^{26}$, and the inverse pole figure to microtexture analysis. EBSD data was also used to generate kernel average misorientation (KAM) maps by MTEX. KAM consists in measurements of the average misorientation angle around a pixel with respect to a set of neighboring points, and was used in order to reveal strain distribution after deformation through routes $\mathrm{A}$ and $\mathrm{B}$.

\subsection{Tensile testing}

Tensile tests were performed with a $98 \mathrm{kN}$ load cell in a EMIC DL10000 machine. The strain rate was $7.06^{*} 10^{-4} \mathrm{~s}^{-1}$ and the specimens were machined in compliance with ASTM E8/ E8M - 16a standard.

\section{Results}

\subsection{Numerical simulation}

The effective strain distribution in the symmetric half of the wire, obtained from computational simulation, is shown in Figure 3, where dimensionless strain is shown in the color scale on the left, and the $\mathrm{X}, \mathrm{Y}$ and $\mathrm{Z}$ axes are shown on the bottom of the figure. The columns (a), (b) and (c) represents $1^{\text {st }}, 2^{\text {nd }}$ and $3^{\text {rd }}$ steps of drawing. It is possible to observe the heterogeneity on the strain distribution in the wire cross-section, along $\mathrm{Z}$ axis. The three steps of drawing presented a deformation gradient from the surface to center of the wire, being the larger deformation adjacent to the surface. Hasani et al. ${ }^{27}$ studied the drawing process of a Cooper wire, and observed a significant difference in microhardness values between surface and wire center. That discrepancy could be associated with processing parameters such as die tool geometry, the chosen lubricant and wire area reduction. Understanding the strain distribution originated during drawing process is important to comprehend its effect on microstructural related phenomena, such as: recrystallization, boundary migration mechanism and $\delta$-phase precipitation in alloy $718^{28}$ and, in this regard, the GBCD. Therefore, it is expected that the aforementioned phenomena respond distinctively along the wire cross-section region. In view of this, the present study analyzed two regions of the cross section of the wire: center and $1 / 2$ of radius of wire.

\section{$3.2 \delta$-phase area fraction analysis}

Table 4 presents the area fraction for $\delta$-phase for each of the processing routes. Comparing routes $\mathrm{A}$ and $\mathrm{B}$, it can be observed that route A presented an overall higher area fraction of $\delta$-phase, which can be associated with the cold deformation cycle prior to a solution annealing step at a sub $\delta$-phase solvus temperature, which leads to an increased precipitation kinetics in every drawing step of route $\mathrm{A}^{28}$. Route $\mathrm{B}$, on the other hand, involves intermediate steps of solution annealing over the $\delta$-phase solvus temperature, despite the longer sub $\delta$-phase solvus solution annealing in the final step, which is associated with the smaller amount of deformation, as can be seen in Figure 1.

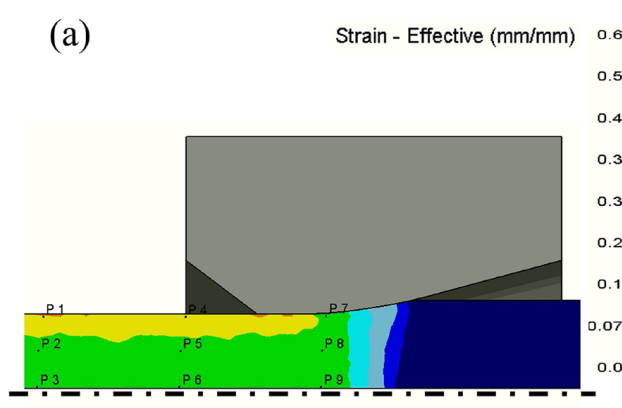

(c) (b)

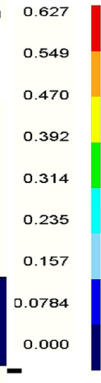

Strain - Effective $(\mathrm{mm} / \mathrm{mm})$

0.35

0.301

0.251

0.201

0.151

0.100

0.000

Figure 3. Computational results showing the effective strain distribution along the wire extension during each drawing step: (a) first step - reduction from 6.7 to $5.9 \mathrm{~mm}$; (b) second step - reduction from 5.9 to $5.4 \mathrm{~mm}$; (c) third step - reduction from 5.4 to $5.0 \mathrm{~mm}$. Strain color scale is on the right of each step figure, and $\mathrm{X}, \mathrm{Y}$ and $\mathrm{Z}$ axes are defined on the bottom of the figure. 
Table 4. Summary of the results regarding $\delta$-phase area fraction (\%), average grain size $(\mathrm{mm})$, and $\Sigma 3^{\mathrm{n}}(\Sigma 3+\Sigma 9+\Sigma 27)$ length fraction $(\%)$ calculated for both routes, $A$ and $B$, both to the center and to the $1 / 2 \mathrm{R}$ position.

\begin{tabular}{cccc}
\hline & $\delta$ fraction $(\%)$ & Grain size $(\mu \mathrm{m})$ & $\Sigma^{n}$ length fraction $(\%)$ \\
\hline Route A center & $1.60 \pm 0.43$ & $5.66 \pm 1.01$ & 43.9 \\
\hline Route A 1/2 R & $2.07 \pm 0.33$ & $4.99 \pm 0.66$ & 47.5 \\
\hline Route B center & $1.16 \pm 0.48$ & $26.32 \pm 5.21$ & 59.4 \\
\hline Route B 1/2 R & $1.40 \pm 0.10$ & $28.98 \pm 7.07$ & 59.5 \\
\hline
\end{tabular}

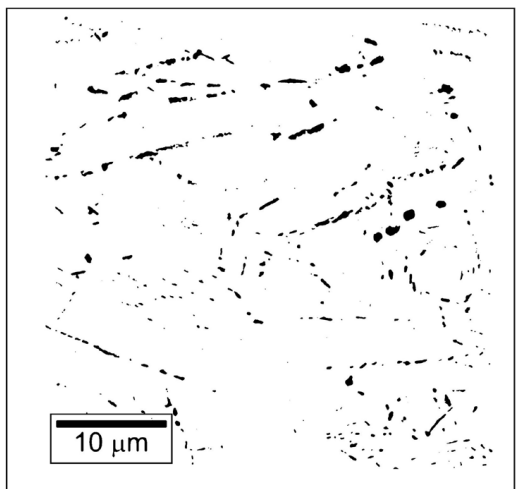

a)

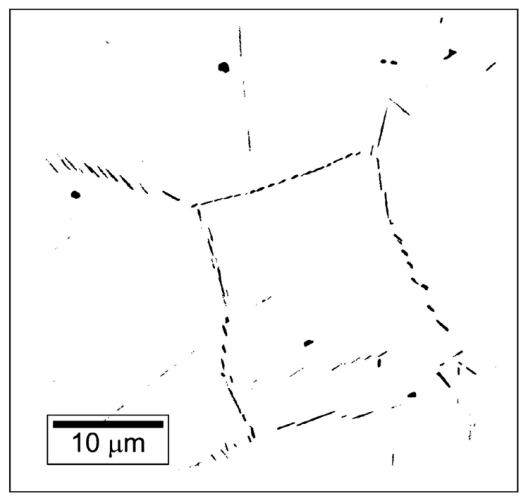

b)

Figure 4. Binarized SEM/BSE images illustrating $\delta$-phase morphology and distribution after the final step of thermomechanical processing for: (a) route $\mathrm{A}$ and (b) route $\mathrm{B}$.

In addition, $\delta$-phase presented different morphologies when comparing route $\mathrm{A}$ and route $\mathrm{B}$ resultant microstructure. The binarized SEM images of the central area of the wires, evidencing $\delta$-phase in black, are presented in Figure 4. For route A (Figure 4(a)), which involved $\delta$ precipitation during the intermediate steps, $\delta$ morphology was more fragmented, induced by migration of recrystallized grains, that cause a morphology change from acicular to spheroidal ${ }^{29}$, both at center and at mid-radius. The aligned distribution followed previously deformed grains, as $\delta$ tends to precipitate preferentially at grain boundaries. Furthermore, the precipitated $\delta$ particles were fragmented in the subsequent drawing steps. Mei et al. ${ }^{29}$ reported that, as the degree of prior deformation increases, due to higher dislocation density within the grain, $\delta$-phase particles tends to be more uniformly distributed during the heat treatment. Jeong et al. ${ }^{30}$ pointed out that cold drawing would favor the round-shaped particles, as well as a shorter annealing time.

On the other hand, for route B (Figure 4(b)), where $\delta$ precipitation occurred only during the heat treatment after the ulterior drawing cycle, resulting particles were predominantly acicular and formed at recrystallized grain boundaries. The lack of previously fragmented particles and the longer final annealing time would favor the precipitation and growth of the needle-like particles, as observed by Jeong et al. ${ }^{30}$.

Other important aspect to be accounted for is the predominant precipitation of $\delta$-phase closer to the surface than to the wire's center, which occurred for both routes, A and B. It is an evident result of the heterogeneity of strain distribution during drawing processing, which is increased towards the surface. Data is summarized in Table 4.

A consequence of the more intense $\delta$-phase precipitation in the intermediate steps of drawing in route $\mathrm{A}$ is a considerably reduction in the average grain size obtained after processing, as can be seen in Table 4. Some authors discuss about that the phenomenon ${ }^{8,11}$ and it is attributed to the pinning effect of $\delta$-phase, restricting grain boundary movement. For route $\mathrm{B}$, the intermediate steps were heat treated over the $\delta$-phase solvus temperature, providing rec pinning effect to grain boundary movement. Only after the last deformation step the heat treatment was conducted under the $\delta$ solvus temperature. This resulted in a bigger grain size and less $\delta$ precipitation.

\subsection{Mesotexture analysis}

Figure 5 shows the grain boundary character distribution maps, where $\Sigma 3$ boundaries are shown in red, $\Sigma 9$ in green, $\Sigma 27$ in blue and random high angle boundaries $(\Sigma>29)$ are shown in black. The total $\Sigma 3^{\mathrm{n}}$ length fraction for each route, both in the center of the wire and in the $1 / 2 \mathrm{R}$ position, are presented in Table 4 . The smaller grain size of route A was accompanied by a lower proportion of $\Sigma 3^{\mathrm{n}}$ boundaries. Route B presented $20 \%$ more $\Sigma 3^{\text {n }}$ boundaries, both for center and $1 / 2 \mathrm{R}$ positions. Randle ${ }^{14}$ states that one of the main conditions for the $\Sigma 3^{\mathrm{n}}$ regeneration process to take place is grain boundary mobility. Therefore, route B, which induced $\delta$ precipitation only after the ulterior drawing step, allowed higher grain boundary mobility, as no $\delta$ particles were introduced in the microstructure after the intermediate annealing heat treatments. It made the $\Sigma 3^{\mathrm{n}}$ regeneration process more effective. Nevertheless, Araújo et al. ${ }^{8}$ studied iterative processing of alloy 718 , comprising cold rolling and solution annealing at $975^{\circ}$ for 70 minutes, and they reported an increase in $\Sigma 3^{\mathrm{n}}$ length fraction concomitant with grain refining due to $\delta$-phase precipitation, which was not observed in the present investigation.

Figure 6 presents the KAM maps of samples from route $A$ at the wire center (a) and at the $1 / 2 \mathrm{R}$ position (b), and from route $\mathrm{B}$ at the center (c) and at $1 / 2 \mathrm{R}$ position (d). Comparing 

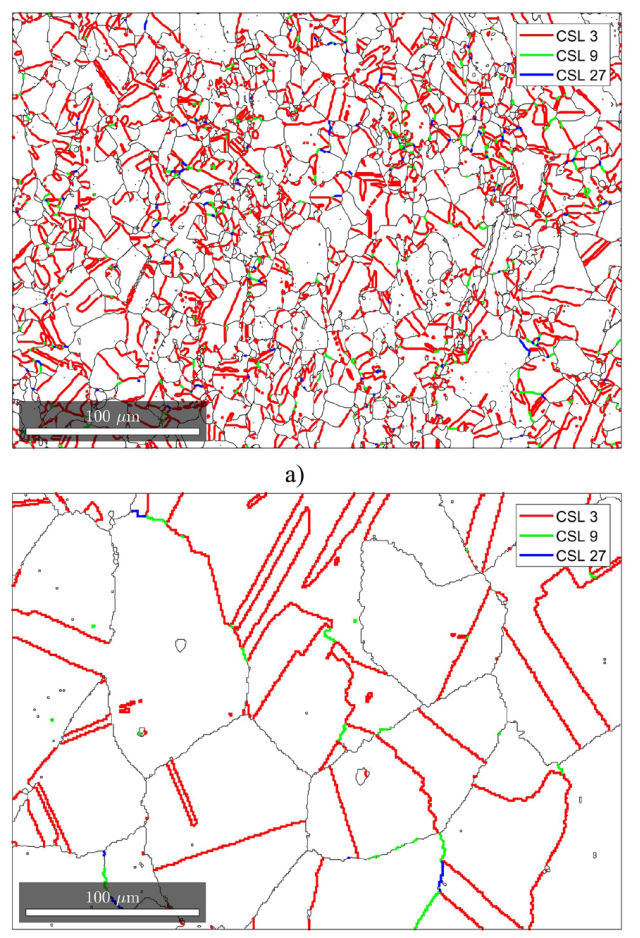

c)

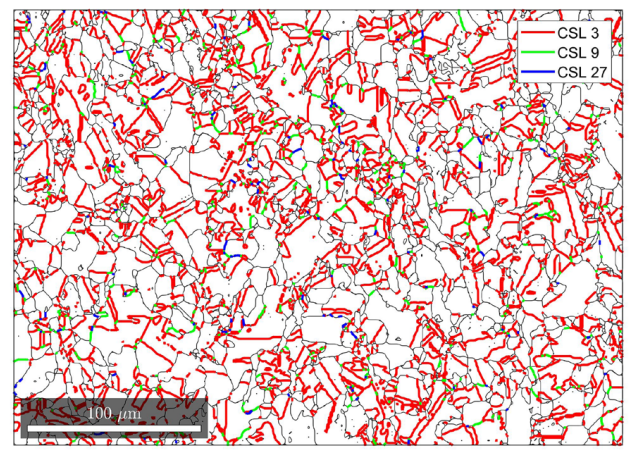

b)

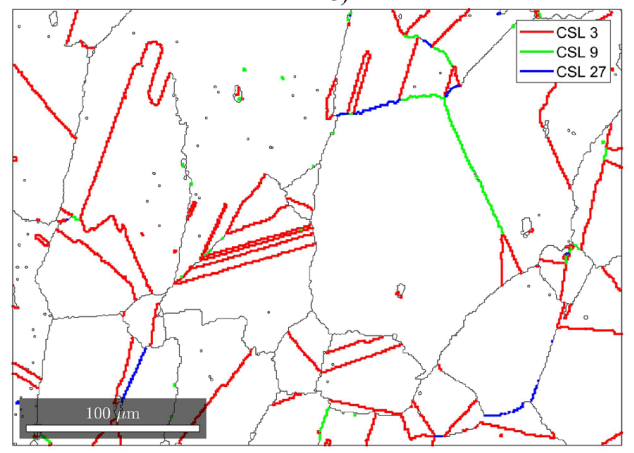

d)

Figure 5. Grain boundary character distribution of route A: (a) in the center of the wire, (b) at 1/2R position; and of route B: (c) in the center and (d) at 1/2R. $\Sigma 3$ boundaries are shown in red, $\Sigma 9$ in green and $\Sigma 27$ in blue. Random high angle boundaries $(\Sigma>29)$ are shown in black.

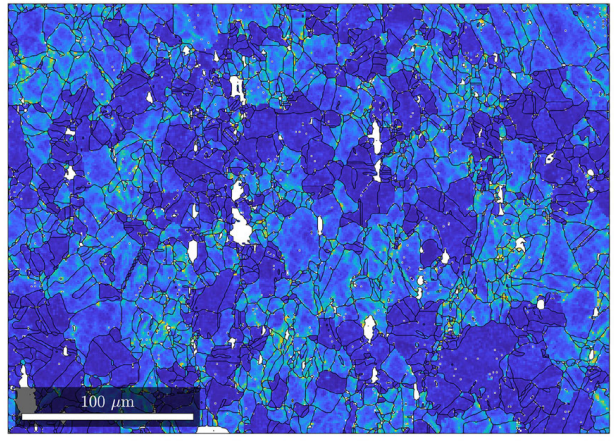

a)

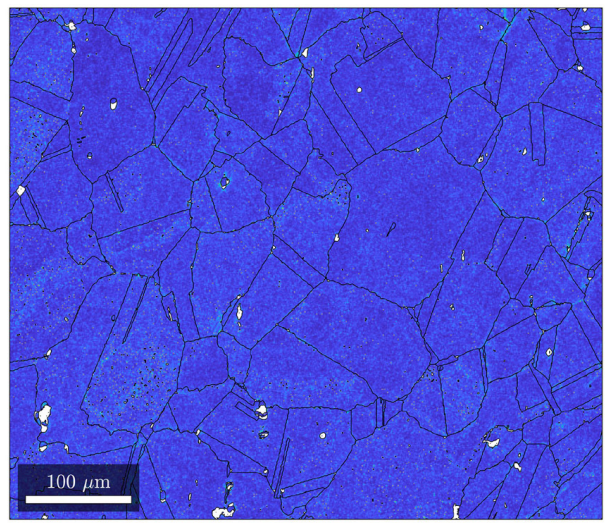

c)

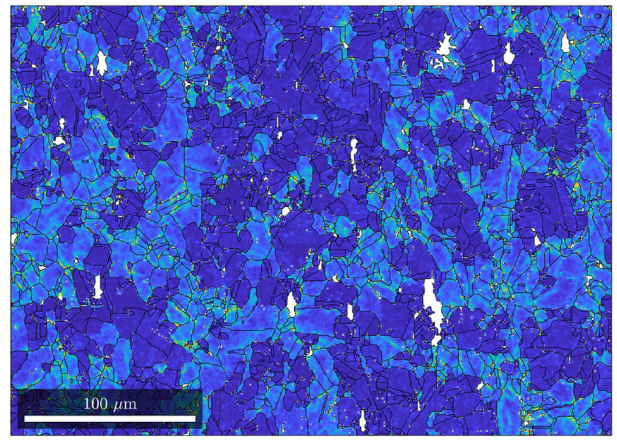

b)

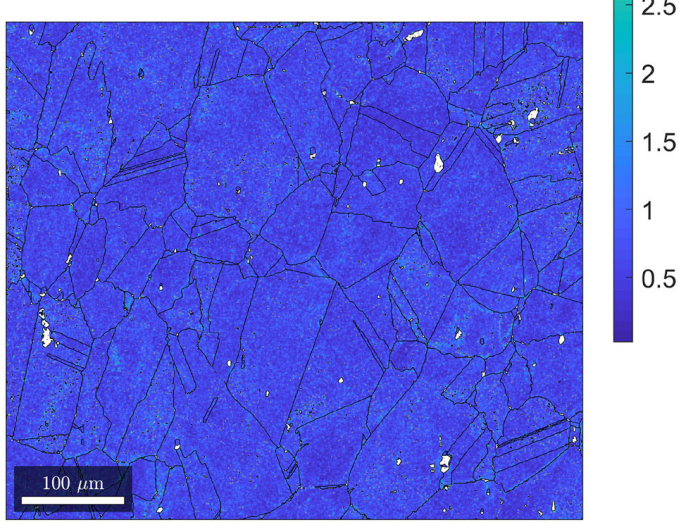

d)

Figure 6. Kernel average misorientation (KAM) maps from route A (a) center and (b) $1 / 2 \mathrm{R}$ position; and from route B (c) center and (d) $1 / 2 \mathrm{R}$ position. 
both routes, it can be stated that the strain distribution and, consequently, the degree of recrystallization are heterogeneous for the sample from route A, showing lower degrees of strain concentrations inside the recrystallized grains (which appear in darker blue in Figure 5 (a) and (b)). Route A was annealed at $975^{\circ} \mathrm{C}$ for 15 minutes between every reduction pass, temperature that favors precipitation of $\delta$-phase. During wire drawing, matrix deforms and dislocations accumulate around the precipitates cyclically, promoting the onset of recrystallization and acting as preferential nucleation sites for more $\delta$. This phenomena annihilates de potential nucleation sites for twins, according to Prithiv et al. ${ }^{31}$. The lower $\Sigma 3^{\mathrm{n}}$ fraction found in route $\mathrm{A}$ is in accordance to that statement. Furthermore, according to Neng-Yong et al. ${ }^{32}$, the complete recrystallization of superalloy 718 , subjected to a $30 \%$ reduction cold rolling followed by annealing heat treatment at $980^{\circ} \mathrm{C}$, is achieved after 30 minutes. Analogous behavior was observed in the present study, which indicates that 15 minutes of annealing time is sufficient only for partial recrystallization, as seen in Figure 6. Nevertheless, the opposite behavior regarding strain distribution was observed on route $\mathrm{B}$, where KAM maps show a very homogenous strain distribution either in the wire center and closer to the surface. It is due to a higher annealing temperature and time between passes and in the final step for route B.

Additionally, as can be seen in Table 4 , route A, in particular, presented an increase of around $8 \%$ in the length fraction of $\Sigma 3^{\mathrm{n}}$ closer to the wire $1 / 2 \mathrm{R}$ in comparison to the center, even though in the $1 / 2 \mathrm{R}$ position the amount of $\delta$-phase was around $25 \%$ higher than in the center. For route $\mathrm{B}$, no significant difference in $\Sigma 3^{\mathrm{n}}$ length fraction between wire center and surface was observed, which can be attributed to the longer solution annealing time after the final step of deformation $\left(975^{\circ} \mathrm{C}\right.$ for 75 minutes), leading to complete recrystallization along the entire wire cross section and enough time to the onset and progress of boundary mobility.

\subsection{Microtexture analyses}

The present investigation evaluated microtexture in alloy 718 based on inverse pole figures (IPF) using as reference the $<100>/ /$ Drawing direction (DD), generated from EBSD mappings data, presented in Figure 7. Both routes, A and B, have shown stronger intensity along the fiber $<110>$ while fibers $<111>$ and $<100>$ are weaker. Samples from route $\mathrm{A}$ and $\mathrm{B}$ exhibited the $<110>$ fiber stronger at $1 / 2 \mathrm{R}$ and at the center of the wire, however, at the $1 / 2 \mathrm{R}$ of the route $B$ sample the maximum intensity texture was deviated from the ideal $<110>$ position, as it can be seen in Figure $7 d$. Recrystallization texture was relatively weak, with maximum intensity of 1.8 for the $<110>$ fiber.

Deformation texture in low stacking fault energy $\left(0-60 \mathrm{~mJ} / \mathrm{m}^{2}\right)$ FCC materials processed by wire drawing is widely discussed in literature and characterized as concomitant presence of $<100>$ and $<111>$ fibers $^{33}$. The intensity of each fiber depends on the plastic deformation the material is subjected to, so that for deformations below $90 \%,<111>$ fiber is stronger ${ }^{34}$. On the other hand, dynamic recovery occurs and leads to a stronger intensity at fiber $<100>$ for more than $90 \%$ of deformation ${ }^{32}$. Other complex fibers are mentioned in the literature, with limited explanations on how they also appear in material

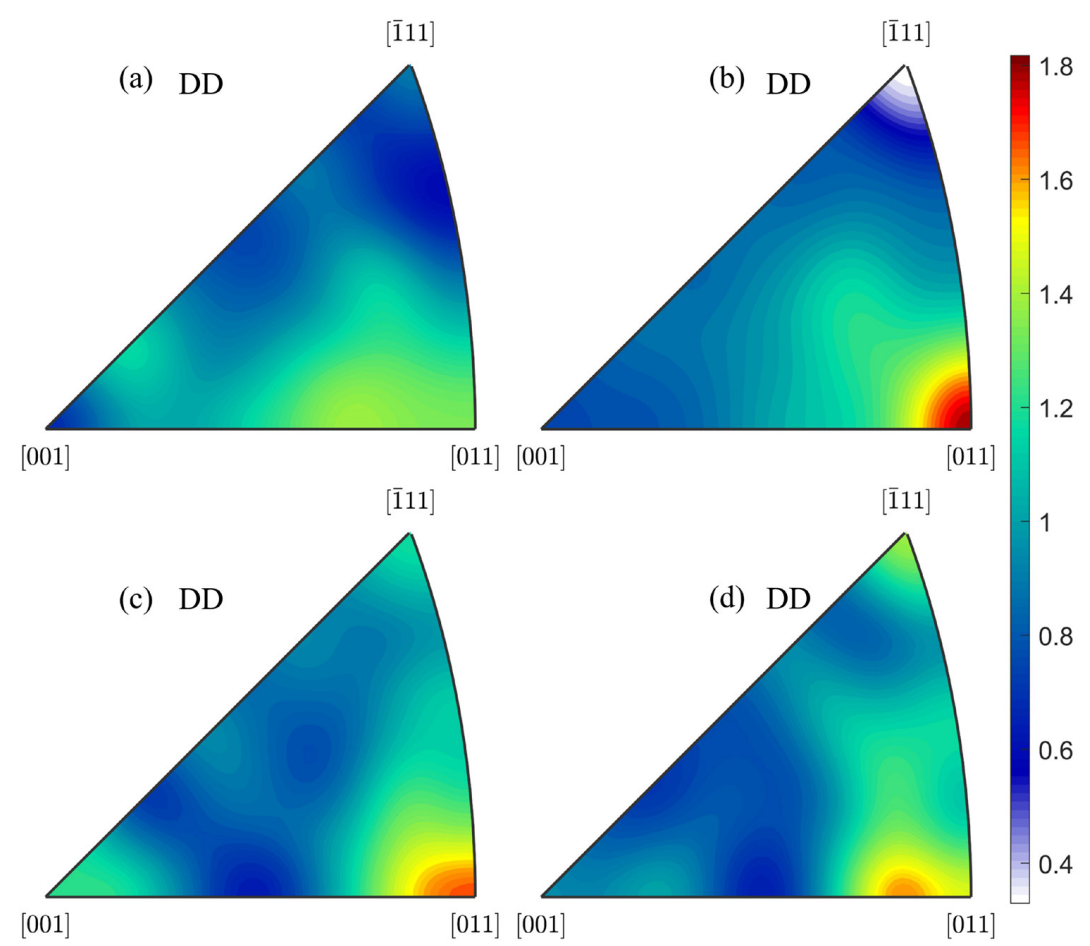

Figure 7. Inverse pole figures, along drawing direction, from (a) route A - wire center; (b) route A - 1/2R; (c) route B - wire center; (d) route $B-1 / 2 R$. 
texture, though. Chen et al..$^{35}$ and Ma et al. ${ }^{33}$, subjected Copper and Silver to deformation below $10 \%$ reduction to investigate the effect of deformation on the evolution of texture in those materials, respectively. They observed that resulting deformation texture was characterized by complex fibers whereas $<111>$ and $<100>$ fibers were present but weaker. GVK et al ${ }^{36}$ verified the presence of $<110>$ fiber associated with deformations inferior than $50 \%$ due to rotation of grains with $<111>$ crystallographic orientation toward $<110>$. Whitis $^{37}$ investigated René DT88 superalloy subjected to deformation degree inferior than $10 \%$ and observed intense deformation texture at fibers $<111>$ and $<110>$, and after recrystallization, $<110>$ fiber became the most intense fiber with 1.8 intensity, which was the case observed in this work

Recrystallization texture after drawing in FCC superalloys is still not well established. Although, from the above, it is possible to establish a correlation between the literature and the recrystallization texture obtained in the present investigation for alloy 718. Last drawing step promoted $15.4 \%$ of deformation, similar to Whitis' study ${ }^{37}$. Therefore, such amount of deformation tends to form complex fibers as a result of deformation texture in FCC materials after drawing, including $<110>$ fiber. Following the recrystallization, configuration of the fibers did not change and it became the material's final texture. It is likely that $<110>$ fiber is stable for a lower deformation amount and that fact would explain the presence of this fiber in alloy 718 . However, further studies are needed since different fiber orientations, other than $<100>$ and $<111>$, in FCC materials, are little addressed in the literature.

\subsection{Mechanical properties}

Tensile tests results are presented in Table 5. For the solution annealed samples, route A produced the higher values of yield (YS) and ultimate tensile strength (UTS). As in the solution annealed condition there are no $\gamma^{\prime}$ and $\gamma^{\prime \prime}$ precipitates, the main hardening mechanism is grain refining ${ }^{38}$. In contrast, there is a decrease in ductility of samples from route $\mathrm{A}$, probably related to increased volume fraction of $\delta$-phase precipitated in the intermediate steps of drawing ${ }^{11}$.

In the aged condition, yield and tensile strength increases drastically, while ductility decreases when compared to solution annealed specimen. There is a slight increase in the yield and tensile strength in route $B$ over route $A$, which is associated with the lower $\delta$-phase precipitation in route $\mathrm{B}$, which derives into the matrix more niobium available for precipitation of $\gamma^{\prime \prime}$ and, consequently, gives rise to improved mechanical properties ${ }^{7,39}$. On the other hand, there is no significant difference in ductility for routes $\mathrm{A}$ and $\mathrm{B}$ in the aged condition.

Table 5. Mechanical properties results for the different processing routes either in the solution annealed and aged conditions.

\begin{tabular}{ccccc}
\hline Sample & Condition & YS(MPa) & UTS(Mpa) & Elongation(\%) \\
\hline A & Annealed & $518 \pm 34$ & $1001 \pm 30$ & $29.1 \pm 6.10$ \\
\hline B & Annealed & $421 \pm 20$ & $914 \pm 44$ & $41.1 \pm 8.70$ \\
\hline A & Aged & $1172 \pm 60$ & $1458 \pm 30$ & $17.5 \pm 3.20$ \\
\hline B & Aged & $1311 \pm 90$ & $1546 \pm 37$ & $18.7 \pm 4.59$ \\
\hline
\end{tabular}

\section{Conclusions}

Based on the results it is possible to conclude:

- The processing with no precipitation of $\delta$-phase in the intermediate steps (route B) was more effective to induce $\Sigma 3$ regeneration mechanism and, consequently, a higher fraction of $\Sigma 3^{\mathrm{n}}$ boundaries. However, this improved boundary mobility lead to a higher grain size than the route with $\delta$ precipitation in the intermediate steps;

- The combination of deformation and the sub-solvus $\delta$ heat treatment during the intermediate steps promoted relevant $\delta$ precipitation, pinning grain boundary movement and resulting in refined grains;

- The wire drawing simulation indicated a deformation gradient from the center to the surface of the wire which was corroborated by the microstructural changes of the cross section of the wire;

- The deformation gradient was associated with variation in the $\delta$ precipitation when comparing center and $1 / 2 \mathrm{R}$ positions. However, regarding the GBCD, only a slight variation was evidenced for route $\mathrm{A}$;

- It was shown that the deformation during the process has influence on the final texture of the material leading to the formation of $<110>$ fiber texture, which was deviated from the common fibers $<100>$ and $<111>$ for wire drawn FCC materials. The route A, annealed for 15 minutes, presented greater difference in intensity of texture between $1 / 2 \mathrm{R}$ and the center of the wire which is associated with the partial recrystallization associated with the low heat treatment time;

- The intermediate $\delta$ precipitation and consequent grain refinement of route A resulted in a higher strength for the solution annealed condition. However, despite the smaller grain size, the elongation was inferior to route $\mathrm{B}$, being related to the $\delta$ precipitation and its role on cavitation and crack propagation. For the aged condition, route $\mathrm{B}$ presented the higher strength in comparison to route $\mathrm{A}$. This was related to the fact that the lower precipitation of $\delta$ made more $\mathrm{Nb}$ available for $\gamma^{\prime \prime}$ precipitation.

\section{Acknowlegedments}

The authors would like to acknowledge the financial support from CAPES, the support from Instituto Militar de Engenharia (IME) and Centro Federal de Educação Tecnológica Celso Suckow da Fonseca (CEFET/RJ) for the EBSD analysis, as well as Escola de Engenharia de Lorena (EEL-USP) for the support on the wire drawing.

\section{References}

1. Donachie MJ, Donachie SJ. Superalloys: A technical guide, 2nd ed. Ohio: ASM International; 2002.

2. Zhang H, Li C, Guo Q, Ma Z, Li H, Liu Y. Improving creep resistance of nickel-based superalloy Inconel 718 by tailoring gamma double prime variants. Scr Mater. 2019;164:66-70.

3. Cruzado A, Gan B, Jiménez M, Barba D, Ostolaza K, Linaza A, et al. Multiscale modeling of the mechanical behavior 
of IN718 superalloy based on micropillar compression and computational homogenization. Acta Mater. 2015;98:242-53.

4. Klotz T, Delbergue D, Bocher P, Lévesque M, Brochu M. Surface characteristics and fatigue behavior of shot peened Inconel 718. Int J Fatigue. 2018;110:10-21.

5. Tarzimoghadam Z, Ponge D, Klöwer J, Raabe D. Hydrogenassisted failure in Ni-based superalloy 718 studied under in situ hydrogen charging: the role of localized deformation in crack propagation. Acta Mater. 2017;128:365-74.

6. Oblak, JM, Paulonis, DF, Duvall, DS. Coherency Strengthening in Ni Base Alloys Hardened by D022 Precipitates. Metallurgical Transactions. 1974;5:143-53.

7. Azadian S, Wei LY, Warren R. Delta phase precipitation in inconel 718. Mater Charact. 2004;53:7-16.

8. Araujo LS, Santos DS, Godet S, Dille J, Pinto AL, Almeida LH. Analysis of grain boundary character in a fine-grained nickelbased superalloy 718. J Mater Eng Perform. 2014;23:4130-5.

9. Sundararaman M, Mukhopadhyay P, Banerjee S. Precipitation of the $\delta$-Ni3 $\mathrm{Nb}$ phase in two nickel base superalloys. Metall Trans, A, Phys Metall Mater Sci. 1988;19:453-65.

10. Singh RP, Hyzak JM, Howson TE, Biederman RR. Recrystallization Behavior of Cold Rolled Alloy 718. In: Loria EA, editor. Superalloys, 718625 and Various Derivatives. Loria, Pennsylvania: The Minerals, Metals \& Materials Society; 1991. p. 205-215.

11. Ramalho Medeiros MA, de Melo CH, Pinto AL, de Almeida LH, Araújo LS. The $\delta$ phase precipitation during processing and the influence on grain boundary character distribution and mechanical properties of superalloy 718. Mater Sci Eng A. 2018;726:187-93.

12. Rezende MC, Araujo LS, Gabriel SB, dos Santos DS, de Almeida LH. Hydrogen embrittlement in nickel-based superalloy 718 : relationship between $\mathrm{g}^{\prime} \mathrm{p}$ g 00 precipitation and the fracture mode. Int J Hydrogen Energy. 2015;40:17075-83.

13. Varela AV, Deus HD, Siqueira MC, Rezende MC, Almeida LH. Oxidation assisted intergranular cracking in 718 Nickel Superalloy: on the mechanism of dynamic embrittlement. Journal of Materials Research and Technology. 2018;7:319-25.

14. Randle V. Twinning-related grain boundary engineering. Acta Mater. 2004;52:4067-81.

15. Randle V. Mechanism of twinning-induced grain boundary engineering in low stacking-fault energy materials. Acta Mater. 1999;47:4187-96.

16. Randle V. Grain boundary engineering: an overview after 25 years. Mater Sci Technol. 2010;26:253-61.

17. Bai Q, Zhao Q, Xia S, Wang B, Zhou B, Su C. Evolution of grain boundary character distributions in alloy 825 tubes during high temperature annealing: is grain boundary engineering achieved through recrystallization or grain growth? Mater Charact. 2017;123:178-88.

18. Prithiv TS, Bhuyan P, Pradhan SK, Sarma VS, Mandal S. A critical evaluation on efficacy of recrystallization vs. strain induced boundary migration in achieving grain boundary engineered microstructure in a Ni-base superalloy. Acta Mater. 2018;146:187-201.

19. Boehlert CJ, Dickmann DS, Eisinger NYNC. The effect of sheet processing on the microstructure, tensile, and creep behavior of INCONEL alloy 718. Metall Mater Trans, A Phys Metall Mater Sci. 2006;37:27-40.

20. Li Q, Guyot BM, Richards NL. Effect of processing parameters on grain boundary modifications to alloy Inconel 718. Mater Sci Eng A. 2007;458:58-66.
21. Baudin T, Etter AL, Penelle R. Annealing twin formation and recrystallization study of cold-drawn copper wires from EBSD measurements. Mater Charact. 2007;58:947-52.

22. Matsushita H, Kuji M, Kuroda T, Aoyama H, Ohfuji H. EBSD Analysis of the Submicron Width Fibber Shaped Grain Copper Fabricated by Drawing. Mater Sci Appl. 2011;2:911-6.

23. Thermo-Calc Software. TCNI8 Ni-based Superalloys DatabaseVersion 8.0. Sweden: Thermo-Calc Software; 2015.

24. Hielscher R, Schaeben H. A novel pole figure inversion method: specification of the $\{$ it MTEX\} algorithm. J Appl Cryst. 2008;41:1024-37.

25. ASTM International. ASTM E112-13: Standard test methods for determining average grain size. West Conshocken: ASTM International; 2013.

26. Brandon DG. The structure of high-angle grain boundaries. Acta Metall. 1966;14:1479-84.

27. Hasani GH, Mahmudi R, Karimi-Taheri A. On the strain inhomogeneity in drawn copper wires. Int J Mater Form. 2010;3:59-64.

28. Mei Y, Liu Y, Liu C, Li C, Yu L, Guo Q, et al. Effects of cold rolling on the precipitation kinetics and the morphology evolution of intermediate phases in Inconel 718 alloy. J Alloys Compd. 2015;649:949-60.

29. Mei Y, Liu C, Liu Y, Zhou X, Li C, Ma Z, et al. Effects of cold rolling on the precipitation and morphologyof $\delta$-phase in inconel 718 alloy. J Mater Res. 2016;31:443-54.

30. Jeong WK, Jo CY, Kim YH, Kim IB. Effects of cold drawing ratio on $\delta$ phase precipitation Behaviors of alloy 718 wire. Met Mater Int. 1997;3:224-9.

31. Prithiv TS, Bhuyan P, Pradhan SK, Subramanya Sarma V, Mandal S. A critical evaluation on efficacy of recrystallization vs. strain induced boundary migration in achieving grain boundary engineered microstructure in a Ni-base superalloy. Acta Mater. 2018;146:187-201.

32. Ye N-Y, Ming C, Shi-Hong Z, Hong-Wu S, Hong-Wei Z. Influence of delta phase precipitation on static recrystallization of cold-rolled Inconel 718 alloy in solid solution treatment. J Iron Steel Res Int. 2019;26:148-53.

33. Ma X, Chen J, Chen Z, Yan W. Evolution of microstructure and texture of cold-drawn polycrystalline $\mathrm{Ag}$ with low stacking fault energy. Sci China Technol Sci. 2015;58:1146-53.

34. Shin HJ, Jeong HT, Lee DN. Deformation and annealing textures of silver wire. Mater Sci Eng A. 2000;279:244-53.

35. Chen J, Ma X, Yan W, Xia F, Fan X. Effect of Transverse Grain Boundary on Microstructure, Texture and Mechanical Properties of Drawn Copper Wires. J Mater Sci Technol. 2014;30:184-91.

36. GVK SS. Tan MJ, Liu Z. Influence of drawing practices on the mechanical. texture and work hardening characteristics of Co-Cr-Ni-Mo wires. Mater Sci Eng A. 2018;713:94-104.

37. Whitis D. Recovery and rercystallization after critical strain in the nickel-based superalloy RENÉ 88DT. Superalloys. 2004;2004:391-400.

38. Anbarasan N, Gupta BK, Prakash S, Muthukumar P, Oyyaravelu R, Kumar RJF, et al. Effect of Heat Treatment on the Microstructure and Mechanical Properties of Inconel 718. Mater. Today Proc. 2018;5:7716-24.

39. Zhang SH, Zhang HY, Cheng M. Tensile deformation and fracture characteristics of delta-processed Inconel 718 alloy at elevated temperature. Mater Sci Eng A. 2011;528:6253-8 